\title{
Turismo, ética e responsabilidade social com crianças e adolescentes
}

Tourism, ethics and social responsibility with children and adolescents

\section{Neio Campos ${ }^{1}$}

1 Doutor em Planejamento Urbano e Regional pela Universidade Federal do Rio de Janeiro. Professor e diretor do Centro de Excelência em Turismo da Universidade de Brasília. E-mail: neiocamp@unb.br 


\title{
Resumo
}

Este artigo tem por objetivo traçar algumas considerações acerca da promoção de ações articuladas de prevenção e enfrentamento da exploração sexual de crianças e adolescentes no turismo. Trazemos o debate com o propósito de discutir a responsabilidade social corporativa e a universalização dos direitos de crianças e adolescentes.

Palavras-chave: Exploração Sexual. Crianças. Adolescentes. Turismo.

\begin{abstract}
This article aim is to draw some considerations on promoting coordinated actions to prevent and combat sexual exploitation of children and adolescents in tourism. We bring the debate with the purpose of discussing social corporate responsibility and universal rights of children and adolescents.
\end{abstract}

Keywords: Sexual Exploitation. Children. Adolescents. Tourism.

\section{Introdução}

Se, ao abordarmos o assunto criança e adolescente, utilizamos a palavra violência é porque este termo representa o que de mais temeroso podemos prever para o futuro desses pequenos cidadãos. Segundo Eisenstein e Souza (1993, p.95), violência é toda ação danosa à vida e à saúde do indivíduo, caracterizada por maus tratos ou cerceamento da liberdade ou imposição da força. Tema difícil e complexo, porém, necessário para a reflexão acerca da proteção de nossas crianças e adolescentes, pois, ainda de acordo com Eisenstein e Souza, são elas, que, por sua maior vulnerabilidade e dependência, são vítimas frequentes. Mas, paradoxalmente, também é o que nos motiva a acreditar que uma sociedade melhor, mais justa, mais feliz pode, sim, não ser apenas utopia. Em outros termos, traz-nos a ideia de valores que se traduzem na conquista da igualdade de direitos à educação, à saúde, à moradia, à vida. Enfim, o direito a ter direitos.

Para este debate, é preciso nos situarmos no Brasil de hoje, em que os avanços sociais, políticos e jurídicos são muitos. Porém, ainda não o bastante para fazer valer 
em sua totalidade a dimensão simbólica da lei - aquela que resguarda o indivíduo-cidadão. Pensar assim requer, pois, refletir acerca da esfera pública na defesa, na manutenção, na criação de direitos e no aniquilamento de privilégios daqueles que se assumem acima das leis - questão das mais relevantes, dada a correspondência entre turismo e exploração sexual de crianças e adolescentes.

Falar desse tema não é tarefa das mais fáceis, pois que dolorosa. Com efeito, a preocupação em combater o crime da exploração sexual de crianças e adolescentes traz imensos desafios. Com eles, o papel de disseminar ações de responsabilidade para todos os agentes da cadeia produtiva do turismo, em consonância com o que diz o Código Mundial de Ética do Turismo:

A exploração de seres humanos, em qualquer de suas formas, principalmente a sexual, e em particular quando afeta as crianças, fere os objetivos fundamentais do turismo e estabelece uma negação de sua essência. Portanto, conforme o direito internacional, deve-se combatê-la sem reserva, com a colaboração de todos os Estados interessados, e penalizar os autores desses atos com o rigor das legislações nacionais dos países visitados e dos próprios países destes, mesmo quando cometidos no exterior (Organização Mundial do Turismo/ONU).

\section{Redes de exploração versus redes de proteção}

As redes de exploração sexual são muitas e nefastas. Para combatê-las, não basta a boa vontade do Estado em manter programas de enfrentamento e combate a esse tipo de crime, mas é imprescindível a participação consciente de organizações e instituições públicas e privadas, que podem se articular em redes de proteção. Para tanto, o Ministério do Turismo mantém o programa Turismo Sustentável e Infância (TSI), com a parceria de algumas instituições. Com o objetivo de identificar a real situação da exploração sexual no turismo brasileiro e adotar ações de proteção a crianças e adolescentes, o programa TSI foi criado em 2004, como resposta a uma solicitação do então presidente da República Luís Inácio Lula da Silva, para que todos os ministérios direcionassem ações de combate a todo tipo de violência contra crianças e adolescentes.

Face à essa demanda, o Centro de Excelência em Turismo da Universidade de Brasília (CET/UnB) adere ao chamado do Ministério do Turismo e passa a desempenhar papel crucial no desenvolvimento do Projeto de Prevenção à Exploração Sexual de Crianças e Adolescentes no Turismo. Também reafirma seu compromisso de trabaIhar para a efetividade da legislação nacional e internacional em defesa dos direitos da criança e do adolescente em situação de violência sexual. Com essa parceria e a responsabilidade que teve durante a vigência do convênio, ao sensibilizar os agentes da cadeia produtiva do turismo para esse grave crime, o CET/UnB destaca o 
papel da Universidade como agente de reforma social e propositora de políticas públicas, pois entende-se que a própria razão de ser da universidade pública brasileira está na sua missão de colaborar para mudanças estruturais na sociedade.

Todos sabemos que a atividade turística é um importante segmento da economia e a que mais cresce no mundo, trazendo dividendos ao país e empregando milhares de pessoas. Porém, e infelizmente, uma boa parte de "turistas" deslocam-se com a ignóbil intenção de "desfrutar prazer" com adolescentes, e até mesmo com crianças. Todos sabemos também que a questão a permear a exploração sexual reside, principalmente, na condição desigual da sociedade. E nesse despertar de interesses e de reflexões é que temos ainda de perceber que, para o sujeito infrator, a prepotência é o princípio de tudo aquilo que passa a ser regulado pela lei do mais forte. Nisso é que reside a dominação - o desrespeito ao Outro - desse sujeito opressor sobre meninas e meninos, que, na sua ingenuidade, comum nessa faixa etária, acreditam no sonho da "vida melhor" que lhe oferecem seus algozes. Essas observações devem ser compreendidas a partir do que disse Kant(1973, AB 43 e A142):

Respeito significa o reconhecimento de um valor que não tem preço, enquanto desrespeito significa o ajuizamento do não valor de uma coisa, ou seja, o tratamento de outro como simples coisa [...]; todas as coisas que podem ser comparadas, podem ser trocadas e têm um preço. Aquelas que não podem ser comparadas, não podem ser trocadas, não têm preço, mas dignidade.

\section{Violação dos direitos humanos}

Considerada grave violação de direitos humanos, a exploração sexual de crianças e adolescentes no turismo deve ser combatida com a conjugação de forças entre todos aqueles que defendem o direito à infância e conscientes de que sua participação pode determinar novos rumos em histórias marcadas pelo sofrimento. Normalmente, o alvo são crianças pobres, vistas por seus algozes como desprovidas de personalidade. Sem educação, elas sofrem a indiferença de muitos. Podemos falar da indiferença moral, que é a desresponsabilização do indivíduo, e da indiferença política, que é a passividade. Interrogar a indiferença é, pois, questionar a relação entre indivíduos, ou, em outros termos, possibilitar a construção de um pacto para mobilizar, articular e sensibilizar entes da sociedade, principalmente aqueles inseridos no segmento do turismo.

Prevenir a exploração sexual de crianças e adolescentes no turismo consiste em mobilizar e articular toda a cadeia produtiva do setor. Para esse embate, o Brasil tornou-se signatário do Código Mundial de Ética do Turismo, elaborado a partir de resolução adotada na Assembleia Geral da Organização Mundial do Turismo (OMT) em 1997. Este 
documento é marco de referência para o desenvolvimento responsável e sustentável do turismo e destaca princípios para guiar seu desenvolvimento no mundo. Tem por objetivo minimizar o impacto negativo do turismo no ambiente e na cultura, ao mesmo tempo em que maximiza os benefícios do turismo. ao promover o desenvolvimento sustentável, aliviar a pobreza e facilitar o entendimento pacífico entre as nações.

O Brasil também estabeleceu lei que se aplica extraterritorialmente, especificamente contra a exploração sexual de crianças e adolescentes. A polícia brasileira trabalha integrada à Interpol para localizar agressores no Brasil e no exterior. Essa ação permite que cidadãos que cometem crimes fora de seus países sejam processados e punidos no território onde praticam o ato delituoso.

Para a promoção de ações de prevenção, há de se levar em conta também a questão ética tanto do ponto de vista corporativo como individual. Com efeito, a preocupação com a ética está presente em todas essas reflexões e nos debates da sociedade contemporânea. Mas aqui, neste tema, sua presença deve ser insistente para o reconhecimento dos direitos das crianças e adolescentes, com foco em sua dignidade e liberdade. Não se deve, pois, deixar que nossos sentimentos se desloquem para a compaixão, porque assim não há reflexão e compreensão adequadas para o reconhecimento do real problema que se apresenta.

A violação da inocência choca, escandaliza e revolta. E para que essas histórias não sejam recorrentes, um dos caminhos pode estar na opção por uma educação humanista, em que esteja vigente a capacidade de identificação e do reconhecimento do Outro. Hannah Arendt falava em "humanizar a humanidade". Nesse sentido, reconhecer que esses pequenos indivíduos também têm direitos. Reconhecer a necessidade de uma educação formadora do espírito livre, de tolerância e compreensão do Outro. Por fim, reconhecer o paradoxo do mundo moderno - ou seja, a sociedade que promete felicidade pelo consumo, mas produz a violência contra crianças e adolescentes cujo cerne está justo nessa infame promessa - para lembrar ao homem sua própria ignorância.

Desse ponto de vista, também acreditamos que "não ver é querer não ver". Essa "cegueira voluntária", que muitas vezes nos leva ao contraditório de nós mesmos, ao comodismo, à omissão. Por isso, compreender que a persistência desse "não ver", do silêncio e do esquecimento podem levar a resultados de uma barbárie. Nisso reside a possibilidade de criar em nós um sentimento capaz de desestabilizar o comodismo e de ver nascer a aversão à grave violação dos direitos humanos de crianças e adolescentes. Assim é que acreditamos, também, que o papel disseminador dessa ação humanizadora de prevenir a exploração sexual de crianças e adoles- 
centes pode dilacerar o nó que está atado na cadeia produtiva do turismo e formar uma grande rede de cidadãos conscientes.

\section{Turismo e infância}

A exploração sexual de crianças e adolescentes no turismo é um problema complexo e envolve muitos coadjuvantes. São visíveis os impactos negativos que esse fato traz para a sociedade e para o destino turístico. Preocupação constante das esferas do governo, essa ação vem sendo combatida no Brasil, com a preocupação focada na garantia dos direitos humanos. O artigo 227 da Constituição Federal de 1988, que resultou da luta da sociedade civil em expor a gravidade desse delito, é um dos instrumentos para lidar com a questão:

É dever da família, da sociedade e do Estado assegurar à criança e ao adolescente, com absoluta prioridade, o direito à vida, à saúde, à alimentação, ao lazer, à profissionalização, à cultura, à dignidade, ao respeito, à liberdade e à convivência familiar e comunitária, além de colocá-los a salvo de toda forma de negligência, discriminação, exploração, violência, crueldade e opressão.

Parágrafo 4ㅇ. - A lei punirá severamente o abuso, a violência e a exploração sexual da criança e do adolescente.

Embora um problema crônico desde tempos remotos, a exploração sexual comercial infanto-juvenil, a partir do debate Constituinte, que consagrou a "nova" Constituição brasileira, em 1988, adquiriu o enfrentamento necessário para seu combate. Várias ações tiveram relevância, como a Comissão Parlamentar de Inquérito da Prostituição Infanto-Juvenil, iniciada em 1993; o Seminário das Américas, realizado em Brasília, em 1996; o Congresso Mundial contra a Exploração Sexual Comercial de Crianças, realizado no Rio de Janeiro, em 2008; entre outros tantos. Esses eventos resultaram em resoluções firmes para impulsionar a ação do Estado rumo à exterminação desse malefício em nossa sociedade.

O Brasil tem ainda como salvaguarda o Estatuto da Criança e do Adolescente - Lei no 8.069/1990 -, que reza em seu artigo 18: "É dever de todos velar pela dignidade da criança e do adolescente, pondo-os a salvo de qualquer tratamento desumano, violento, aterrorizante, vexatório ou constrangedor". E ainda em seu artigo 5ㅇ:

Nenhuma criança ou adolescente será objeto de qualquer forma de negligência, discriminação, exploração, violência, crueldade e opressão, punido na forma da lei qualquer atentado, por ação ou omissão, aos seus direitos fundamentais.

Alguns de seus artigos estão direcionados explicitamente à indústria do turismo, como 
o artigo 70, que transforma em dever de todos prevenir a ocorrência de ameaça ou violação dos direitos da criança e do adolescente. O artigo 82 também é taxativo: proíbe a hospedagem de criança ou adolescente em hotel, motel, pensão ou estabelecimento semelhante sem autorização ou acompanhamento dos pais ou do responsável. Se não houver o cumprimento dessa norma, o estabelecimento poderá ser autuado, estando o sujeito a multa de 10 a 15 salários e a ter cassada a licença de localização e de funcionamento. O ECA também estabelece pena de quatro a dez anos para quem submeter criança ou adolescente à prostituição ou à exploração sexual.

Mas, como sabido, as questões que permeiam a exploração sexual residem, principalmente, na condição desigual da sociedade e em disparidades econômicas, estruturas socioeconômicas injustas, falta de educação, entre outras. Meninas e meninos pobres, seduzidos pelo sonho de uma vida melhor, perdem a juventude, aliciados por agenciadores inescrupulosos, infiltrados em toda a cadeia produtiva do setor turístico.

\section{Respeito à infância}

Chamam a atenção também as relações de poder, caracterizadas pela subjugação do Outro que se encontra em situação inferior. Essas condições estão impostas, histórica e culturalmente, pela concepção arraigada desde tempos imemoriais de que mulheres e crianças devem ser submissas e dominadas por homens. Essa situação reforça o pensamento machista, que desencadeia as circunstâncias que levam a que crianças e adolescentes sejam desrespeitados e sua sexualidade colocada como mercadoria.

A esse entendimento, acrescente-se o que afirma Lajolo a respeito da infância:

Enquanto objeto de estudo, a infância é sempre um Outro em relação àquele que a nomeia e estuda. As palavras infante, infância e demais cognatos, em sua origem latina e nas demais línguas derivadas, recobrem um campo semântico estreitamente ligado à ideia de ausência da fala [...] Assim, por não falar, a infância não se fala e, não se falando, não ocupa a primeira pessoa nos discursos que dela se ocupam. E, por não ocupar esta primeira pessoa, isto é, por não dizer eu, por jamais assumir o lugar de sujeito do discurso, e, consequemente, por consistir sempre um ele/ela nos discursos alheios, a infância é sempre definida de fora (2001, p 229-230).

Negligência, omissão e maus-tratos sofridos em casa também aumentam a vulnerabilidade dessas crianças e adolescentes, que, geralmente discriminados, não têm voz para se fazer ouvir, pois não são vistos como seres humanos ou cidadãos completos. É fato que muitas dessas crianças vitimadas pelo exploração sexual vêm de lares com registros de abusos entre parentes, inclusive pais. É a ultrapassagem de todos os limites de que o ser humano pode ser capaz. Nada justifica impor práticas 
sexuais por meio da violência física, da ameaça ou da coação. Como também nada justifica uma mãe negociar suas filhas em troca de comida, roupa, sapato e entregá-las a cafetões e cafetinas, vendendo-lhes a inocência.

A exploração sexual comercial de crianças e adolescentes é um crime que remonta à Grécia Antiga. Sabe-se que, naquela época, meninas escravas de apenas cinco anos de idade eram comercializadas para a prostituição. Esse triste fenômeno foi tomando novas formas e sofrendo alterações de acordo com o contexto em que estava inserido. Hoje, é uma espécie de tentáculo do crime organizado, ligado diretamente ao tráfico de drogas, de armas e de pessoas. Absurdamente, há em torno dessa prática uma rede de silêncio, conivência, omissão, impunidade, além da violência, sustentada pelo lucro e que precisa ser rompida. E, muito infelizmente, o Brasil figura como um dos principais destinos internacionais para a prática da exploração sexual no turismo. Segundo Faleiros:

A rede autoritária de exploração sexual de crianças e adolescentes está centrada no lucro comercial que se possa obter com o trabalho do corpo da criança ou adolescente na sua transformação e submissão em mercadoria humana para benefício sexual do cliente e benefício comercial dos proprietários do comércio e aliciadores (1988).

Os dados falam por si. Cerca de um milhão de crianças entram para o mercado do sexo no mundo a cada ano, segundo estimativas do Unicef. No Brasil, o número pode chegar a pelo menos 100 mil crianças e adolescentes explorados sexualmente, conforme levantamento divulgado, em 2001, no relatório Unicef "Lucrando com o abuso".

No Brasil, o Nordeste é a região onde está registrado o maior número de casos de exploração sexual de crianças e adolescentes. Isso se deve à grande demanda de turistas nacionais e estrangeiros, atraídos pelas belas praias. Com a maior costa litorânea do País, natureza rica e diversificada, o Nordeste é um dos mais concorridos destinos turísticos do Brasil. Contudo, a prática é corriqueira também nas demais cidades litorâneas, em garimpos, nas estradas e em pequenas cidades do interior. Essas redes de exploração diversificam-se de acordo com o mercado de usuários, podendo ser formadas redes de luxo para altos executivos, empresários e políticos e também redes que se voltam para a classe média ou a de baixa renda.

Identificando-se os locais dessa prática, fica mais fácil observar e direcionar o olhar para mais além do que normalmente costumamos ver. Um olhar que possibilite uma responsabilização perante a vulnerabilidade de crianças e adolescentes expostos a fatores de risco, como a exploração sexual.

Crianças ou adolescentes vítimas de abuso ou exploração sexual desenvolvem uma noção diferente do mundo e de seus relacionamentos afetivos. Convivem com a culpa 
e a baixa estima e podem ter dificuldades de construir relações duradouras. Ao sofrer abuso ou exploração sexual, crianças ou adolescentes têm uma visão deturpada do sexo e podem carregar transtornos psicológicos para o resto da vida. Podem ser afetados por sérios problemas físicos, emocionais, cognitivos e sociais e por enfermidades, como doenças sexualmente transmissíveis, abortos espontâneos e outros.

Sob a perspectiva da criança vitimada, Summit $(1983)^{2}$, refere-se à síndrome de adaptação da criança vítima de abuso sexual, afirmando que ela pode se adaptar à situação abusiva. Isso significa que, se, ao buscar ajuda, a criança não a encontrou, não foi protegida, resta a ela como única opção aceitar a situação como forma de sobrevive $r$, identificando-se com seu agressor e aceitando suas imposições. Seu agressor é a pessoa que ela mais teme, mas, ao mesmo tempo, confia.

\section{Considerações finais: Sensibilizando os profissionais do turismo}

A responsabilidade social de conter a exploração sexual de jovens no turismo envolve vários aspectos relacionados à ética, à transparência, à sociedade, ao governo, entre outros. Com relação aos profissionais do turismo, é preciso primeiramente identificar qual seu grau de conhecimento sobre os direitos das crianças e dos adolescentes, bem como sobre o comércio sexual destes.

Sensibilizar para a questão é o passo seguinte. É preciso que o profissional do turismo saiba que acabar com a exploração sexual de crianças e adolescentes nos pontos turísticos requer o envolvimento de muitos atores, e que a dedicação a esse tema pode atrair outras pessoas e familiares desses profissionais e envolver também fornecedores e parceiros. Os profissionais do turismo têm ainda uma importante ferramenta para orientar sua participação no enfrentamento desse crime - trata-se do Código de Conduta para a Proteção da Criança contra a Exploração Sexual em Viagens e Turismo (The Code). $\mathrm{O}$ documento orienta como empresas de turismo podem e devem atuar para prevenir esse crime, assumindo sua responsabilidade como agente social.

O Código foi elaborado pela Articulação Internacional contra a Prostituição, Pornografia e Tráfico de Crianças e Adolescentes (ECPAT), em parceria com a Organização Mundial de Turismo e o Fundo das Nações Unidas para a Infância (Unicef) e já recebeu a adesão de empresas de turismo de 32 países, entre eles o Brasil. Podem associar-se agências de viagens e de eventos, operadoras, associações, sindicatos, cooperativas, casas noturnas, restaurantes e meios de hospedagem.

2 Citado no projeto Prevenir é poder. A Justiça e a Terapia Familiar na Construção da Paz e a Não Violência. In http:// prevenirepoder.com.br/Pag_18_Apostila\%20final.htm\#VIOL\%C3\%8ANCIA\%20CONTRA\%20CRIAN\%C3\%87AS. Consulta em 17/07/2012. 
O Código estabeleceu ações que devem ser cumpridas pelas empresas que se associam a ele. $O$ documento exige que as empresas expressem abertamente seu repúdio à exploração sexual infantil, rechacem todo tipo de contato com redes de prostituição e capacitem seus funcionários sobre regras de ética. Todo profissional da cadeia produtiva do turismo deve ter amplo conhecimento dessas ações para que possa fazer valer seus princípios.

Com isso, podem ser compartilhados esforços, entendimentos e competências para o enfrentamento da exploração sexual infanto-juvenil. Para tanto, é preciso conhecer e reconhecer a criança e o adolescente como sujeitos de direitos e entender que eles não podem ser submetidos, mesmo que por aparente vontade própria, à exploração sexual. No combate a essa prática não se pode aceitar que a pobreza e a miséria possam servir de justificativa para não agir no enfrentamento dessa questão.

Essa reflexão obriga-nos a "querer ver" e a "querer ouvir" este problema e a colocar em foco questões estruturantes da sociedade, dando visibilidade a esses pequenos cidadãos, com seus direitos a ter direitos. É reforçar a crença de que existe uma relação direta entre o mundo real, objetivo, concreto e o sujeito, entre a objetividade e a subjetividade, pois nosso papel no mundo "não é só o de quem constata o que ocorre, mas também o de quem intervém como sujeito de ocorrências" (FREIRE, 200, p.79). É buscar as possibilidades de legitimar uma cultura de paz. É, como disse Benjamim (1985, p.223): “Não existem, nas vozes que escutamos hoje, ecos das vozes emudecidas?".

\section{Referências}

BENJAMIM. Walter. Obras escolhidas, volume 1. São Paulo: Brasiliense, 1985.

EISENSTEIN, Evelyn e SOUZA, Ronald Pagnocelli de. Situações de riscos à saúde de crianças e adolescentes. Rio de Janeiro: Vozes, 1993.

FALEIROS, Vicente. Redes de exploração sexual e redes de proteção. In Anais do 9‥ Congresso Brasileiro de Assistentes Sociais, 1988.

FREIRE, Paulo. Pedagogia da indignação: cartas pedagógicas e outros escritos. São Paulo: Editora Unesp, 2000, p.79.

KANT, I. Fundamentação à metafísica dos costumes. São Paulo: Abril Cultural, 1973, AB 43 e A142.

LAJOLO, Marisa. Infância de papel e tinta. In: FREITAS, Marcos Cezar (Org.). História social da infância no Brasil. São Paulo: Cortez, 2001. 